\title{
The Spread and Sequence Exploration of the isolated Avian Influenza viruses H5N1from backyard ducks in Asyut-Egypt
}

\author{
Moemen A. Mohamed ${ }^{1}$, Mohamed A. Gamal ${ }^{2}$ \\ ${ }^{1}$ Poultry Dis. Dept., Col Vet Med., Assiut Univ., Assiut, Egypt \\ ${ }^{2}$ Provisional Lab, Assiut, Animal Health Research Institute
}

\begin{abstract}
Avian Influenza infection is an important devastating disease among domesticated birds so our goal is to evaluate the prevalence of influenza A virus (H5N1) among backyard ducks as well as the genetic changes will be happened among the H5 gene using sequence analysis. Fifty samples of cloacal swabs were gathered from backyard ducks in Asyut Province, Egypt exposed to RNA extraction followed by H5 and N1 identification using realtime-RT-PCR and one-step RT-PCR respectively finalizing by complete sequence analysis of H5 gene for 5 isolates.

14 samples out of 50 examined samples were positive for H5N1 subtype. The deduced amino acids of the sequenced hemagglutinin (HA) genes seen that the examined isolates have two molecular characteristics of HPAIV in the polybasic amino acids of the cleavage site, including EKRRK/KR*GLF) which is a common shape for multicleavage site in Egypt since 2013. Several amino acid substitutions were observed, especially at D43N, S120D, I151T and R162K which is suggestive the examined viruses belonged to 2.2.1.2 clade. Phylogenetic analyses of the HA revealed that the examined strains were genetically belonged to 2.2.1.2 clade. Homology percentages revealed a distant of the examined strains from the vaccinal strains that commonly used in Egypt, which the lowest homology was recorded with A/chicken/Mexico/232/94 vaccinal strain.
\end{abstract}

This study affirmed the potential role of backyard ducks as a reservoir for AI/H5N1 clade 2.2.1.2 in Asyut-Egypt which may help in continuation and adaptation of AI/H5N1 virus in the target area and represent a potential danger to both poultry and humans. So, a regular survey to illuminate the spread of HPAIV H5N1 among commercial poultry and backyard birds should be applied.

Keywords: AI H5N1 . Ducks . Haemagglutinin gene. Sequence . phylogenetic analysis

\section{BACKGROUND}

Avian influenza (AI) is a greatly transmittable respiratory disease affecting poultry caused by influenza A virus that belonged to family Orthomyxoviridae, and represents a major threat to the poultry industry worldwide[1].Influenza A virus are divided into 16 haemagglutinin (HA) subtypes and 9 neuraminidase subtypes infect wild and domestic birds with the exclusion of the newly characterized H17N10influenza virus that was isolated from bats [2].

There has been an increase in the population of birds infected by highly pathogenic (HP) avian influenza (AI) since the 1990s [3]. The most recent HPAI outbreaks of H5N1 begin in China and Hong Kong since 1996 then spread in 2003 to different localities in the world including South-East Asia, the Middle East, Europe and in 2006 transmitted rapidly to Africa [4].Egypt formally reported its first outbreak in poultry in February2006 (http://www.oie.int/eng/info_ev/en_AI_factoids_ H5N1_Timeline.htm). After that, clade 2.2 viruses have spread between domesticated birds all over the country and the HPAI H5N1 virus was stated endemic in Egypt inJuly 2008 (http://www.oie.int/animal-health-in-the-world/web-portal-on-avian-fluenza/about-ai/h5n1-timeline/).

Domestic ducks play a significant role in the epidemiology of HPAI H5N1 viruses which are the usual reservoir of avian influenza viruses[5,6] and are a threat to the presence of H5N1 virus infections among domestic poultry[7,8]. The replication of the majority AIV is generally constrained to the intestinal duct of wild aquatic birds, resulting in no obvious clinical signs. However, certain H5 and $\mathrm{H} 7$ strains may cause noticeable signs and death[3]. 
It has been evaluated that more than 35 million ducks yearly are raised in the backyard division, and an additional five millions are reared in the commercial sector in Egypt[9].In the backyard region(chickens, ducks, geese, turkeys and infrequently pigeons) are usually raised in contact within the same house[10]. As well as. The Egyptian live poultry markets, where birds of several species and ages from different places are present for trade and slaughter, giving a chance for viral transmission between poultry species that permit a possibility for AIV genome to changed[11].

The control plans have been concentrated on vaccination programs with inactivated H5N1 or H5N2 viruses in the contaminated countries in addition to virus investigation in the poultry sector, as well as the elimination of infected birds[12]. These plans have extensively reduced outbreaks. However, survey statistics disclose continuous circulation of the virus in spite of immune stress formed from vaccination in commercial farms, family backyards and live poultry markets[13]which may lead to its development into multiple new genotypes.

The HPAI H5N1 viruses clade 2.2 spreading in Egypt since 2006 are highly pathogenic to chickens and can be fatal to ducks[14]. From the time when becoming endemic in Egypt, the virus has extended from farm to farm, even under the immune pressure of vaccination, which may lead to its mutation[15].

To evaluate the suggestion that ducks responsible for the continuation and spreading of avian influenza (H5N1)viruses, we conducted a research describing virus presence in backyard ducks that have contact with chickens in Asyut, Egypt with complete sequence characterization of the haemagglutionin gene.

\section{Materials AND Methods}

\section{Samples}

Beginning in January 2015, ducks in backyards in Asyut Province, Egypt, suffered from ecchymosis on the bill and torticollis as suggestive signs for HPAIV infection, as shown in Fig. 1Aand1B.

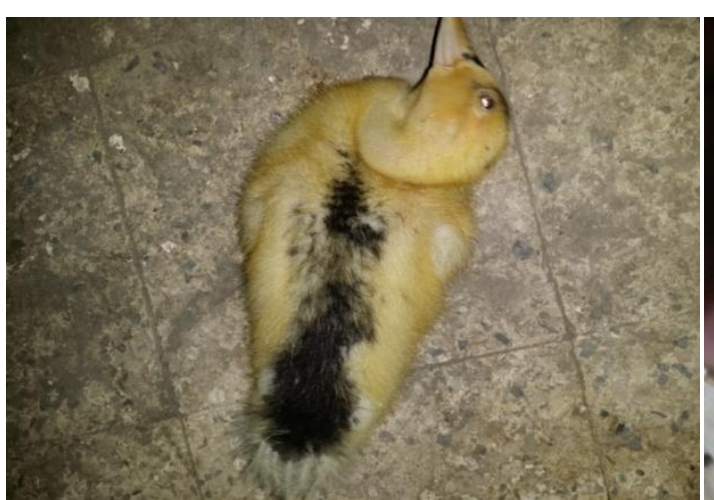

A

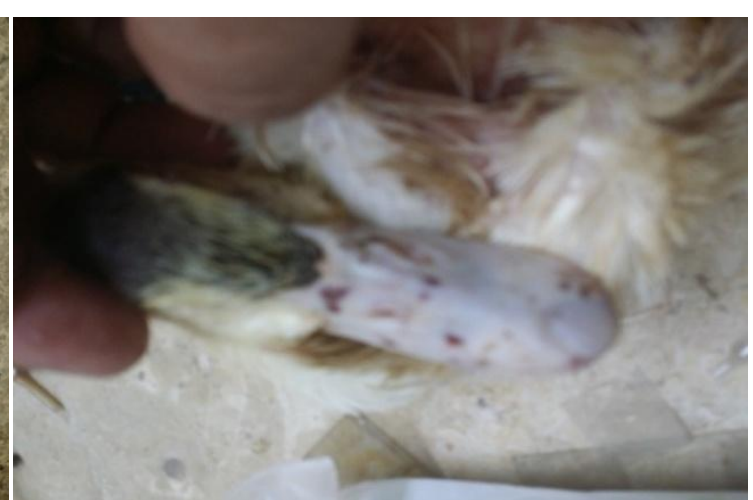

B

Fig. 1. Naturally infected ducks by HPAIV H5N1. (A) Nervous signs (B) Echymotic hemorrhages on the duck bill

Cloacal swab samples were collected from 50 backyard ducks during 2015 in Asyut province-Egypt. The samples were placed in a transport medium contained phosphate-buffered saline (PBS), penicillin $(2,000 \mathrm{IU} / \mathrm{ml})$ and streptomycin $(2,000 \mathrm{ug} / \mathrm{ml})$. Samples were right away transported to the laboratory at $4^{\circ} \mathrm{C}$ then kept at $-70^{\circ} \mathrm{C}$ for the late examination[16].

\section{AIVs detection and subtyping}

\section{Viral RNAs extraction}

Cloacal swabs were vortexed at $3000 \mathrm{r} / \mathrm{min}$ for $15 \mathrm{~s}$ then centrifuged at $3000 \mathrm{r} / \mathrm{min}$ for $10 \mathrm{~min}$. Viral RNAs from resultant supernatant were extracted by the use of Thermo Scientific GeneJET Viral RNA Purification Kit (Cat. No. K0821) of 50 reactions was used.

\section{Amplification}

In order to characterize the H5N1 virus causing this out break, the hemagglutinin (HA) gene of the virus in our samples was analyzed using sets of H5 HAprimers(LH1 
The Spread and Sequence Exploration of the isolated Avian Influenza viruses H5N1from backyard ducks in Asyut-Egypt

ATATACGACTACCCACARTATTCAG, RH1 AGACCAGCTAYCATGATTGC)and probe with the following sequence FAM-TCW ACA GTG GCG AGT TCC CTA GCA-BHQ-1[17] with thermo scientific verso 1- step QRT- PCR kit plus Rox vial was used.

For analysis of NA1subtype with a set of primers (TCARTCTGYATGRYAAYTGG, GGRCARAGAGAKGAATTGCC) and one step RT-PCR was used with the expected amplicon size 245-bp for positive samples[18]. RT-PCR products of neuraminidase (NA) gene reactions were detected using electrophoresis in a 1.5\% agarose gel.

\section{Genetic and phylogenetic analyses}

Full length amplification of the segment 4 of HA gene from the position 7 bp to position 1754 for the 5 isolated viruses was done using Qiagen one-step RT-PCR Kit (Cat. No. 210212) of 100 reactions (Qiagen-USA) with the aid of the following primers (4FV2;AGCAGGGGTTCAATCTGTCAAAA,4RV2, AGTAGAAACAAGGGTGTTTTTAACTA)[19]. The reactions were done in a thermal cycler (Mastercycler, Eppendorf, USA). The RT reaction was carried out in three steps; firstly, $45^{\circ} \mathrm{C}$ for 30 min followed by 15 -min at $95^{\circ} \mathrm{C}$. Secondly, 35 cycles; each one consists of $94^{\circ} \mathrm{C}$ for $45 \mathrm{Sec}, 58^{\circ} \mathrm{C}$ for $30 \mathrm{Sec}$ and $72^{\circ} \mathrm{C}$ for $2 \mathrm{~min}$. Thirdly; final extension for 10 minutes at $72^{\circ} \mathrm{C}$.

RT-PCR products were purified using a QIAquick PCR purification kit (Qiagen) then sequenced using the Big Dye Terminator Cycle Sequencing Ready Reaction kit (Applied Biosystem) on Applied Biosystems 3730xl DNA analyzer, according to the manufacturer's instructions.

The Phylogenetic examination was originated on the full gene sequences of the segment 4 of $\mathrm{H} 5$ gene. Sequences of the H5N1 isolates used for comparison were getting from GenBank. Phylogenetic trees were created using the MegAlign(DNA STAR Lasergene 8, Madison, WI) depending on the neighbor-joining method by means of bootstrap analysis with 1000 replications in[20].The nucleotide and deduced amino acids'alignment were carried out using BioEdit software version 7.1.9[21].

\section{RESUltS}

In total, $14 \mathrm{H} 5$ positive samples were identified using rRT-PCR from 50 collected samples with a percentage of (28\%) Fig 2.Conventional RT-PCR technique targeting the neuraminidase (NA) gene found that all the H5 identified strains were positive for NA1 subtype (Fig.3).

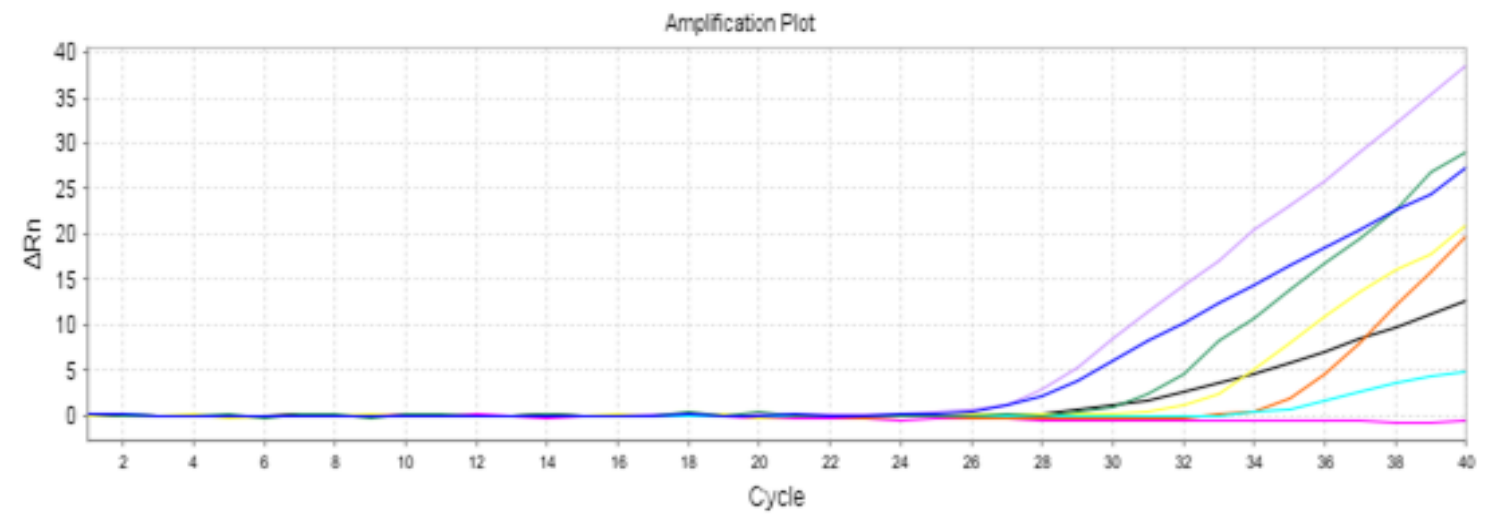

Fig. 2.

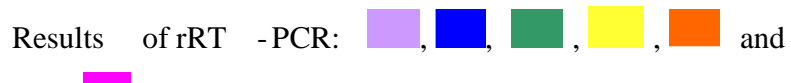
are positive samples while and are positive and negative control respectively. 


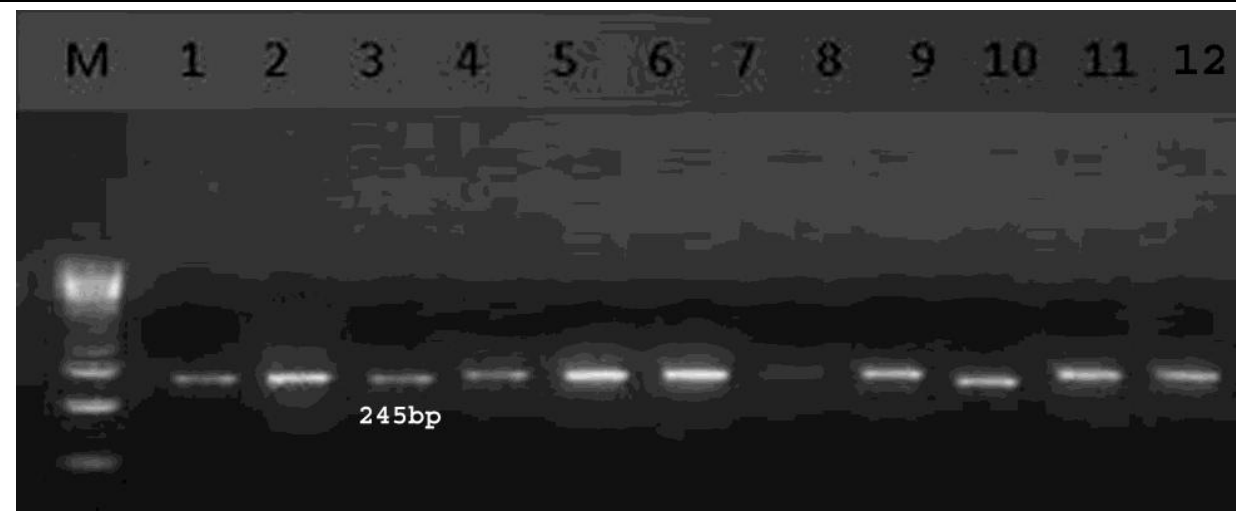

Fig. 3. Representative result of RT-PCR result for 12 positive NA1 subtype samples by partial amplification of coding region neuraminidase gene subtype1

\section{Sequence and phylogenetic analysis}

The selected H5 positive samples yield the expected HA gene amplicon approximately 1700bp. The coding sequence of those five H5 strains have been produced from the yielded amplicons then submitted to GenBank under the following accession numbers KU229976under name A/duck/Egypt/1/2015 (H5N1) and KU357036-KU357039 under the names from A/duck/Egypt/2/2015 (H5N1) to A/duck/Egypt/5/2015 (H5N1) respectively.

\section{Analysis of deduced amino acids}

Analysis of the deduced amino acids disclosed the presence of multiple basic amino acid motifs at the cleavage site of the HA molecule ${ }^{6324}$ PQGEKRRKKR/GLF ${ }^{333}$, in four samples and PQREKRRK/KR*GLF in one isolate Fig.4 which indicated the highly pathogenic nature of the examined strains. Amino acids 222Q and 224G (H5 numbering) were found in the examined strains, which is indicative of the preference of examined isolates to avian $\alpha 2,3$ receptor binding (Fig. 4).

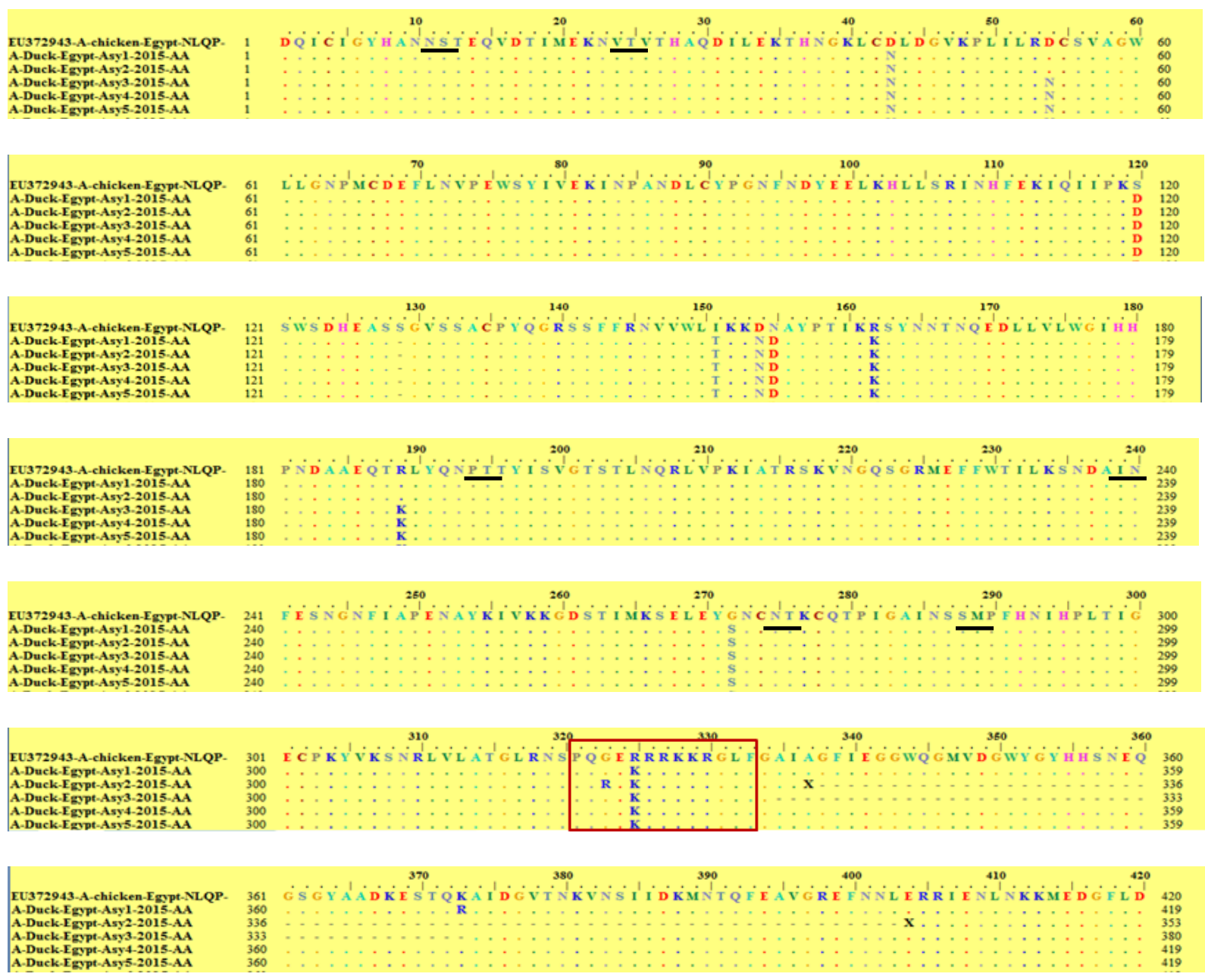


The Spread and Sequence Exploration of the isolated Avian Influenza viruses H5N1from backyard ducks in Asyut-Egypt

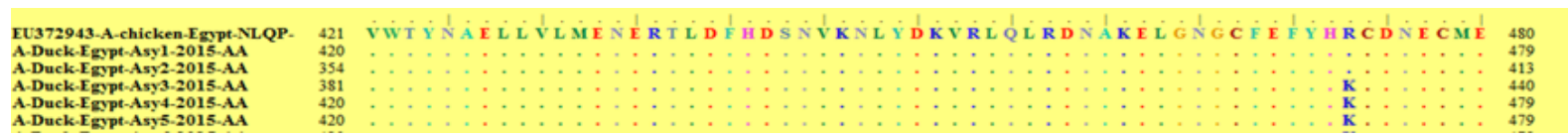

Fig. 4. Multiple amino acid sequence alignment of HA gene of our circulating strains in comparison with Egyptian A/chicken/Egypt/06207-NLQP/2006. The Dot (.) represents identity, whereas single alphabet represents the difference in the amino acid sequence. The underlined residues are potential glycosylation sites. The alignment was generated using the Bioedit program.

The AI viruses have five antigenic sites in the HA gene and anymutationin these regions cause a significant role in the development of H5N1[22]. From the obtained results of sequencing, we have not seen changes in antigenic site A (S133, R140and S141). One change observed in the N154D that belonged to antigenic site $\mathrm{B}$ as well as conservation of amino acids sequences at antigenic site $\mathrm{E}$ was mentioned in the examined strains (L71, I83 andA86) that indicative their belonging to clade 2.2.1.

Egyptian H5N1 strains having a character of conserved antigenic sites C and D especially in the following amino acid places (N94, S120, R162, E227, N252, T263 and I282, H5 numbering) as antibody-binding sites[23]. Our isolates revealed two mutations in the antigenic site C and D (S120D, R162K).

The five examined viruses have four mutations that occurred at the same sites, S120D, I151T, D154N and R162K that were common with viruses belonging to 2.2.1.2. two of these mutations (154 and162) were distinguishing the new viruses from the earlier 2008-09 viruses (24)

A new cluster was emerged from clade 2.2.1/C having several mutations that distinct from formerly circulating subclades(25). As shown in Fig. 4, all the 5 examined viruses are suggestive to be placed in this new cluster due toits having the following mutations incomparable to A/chicken/Egypt/06207NLQP/2006(H5N1) D43N, S120D, I151T, and R325K, which were seen previously in subclade 2.2.1 but not subclade 2.2.1.1. In addition tomutations in N155D and G272S that were common in the new cluster and mentioned before in subclade 2.2.1.1, but not 2.2.1(25).

\section{Nucleotide similarity and Phylogenetic analysis}

The nucleotide sequences revealed the high relationship between the 5 examined strains with a percentage (>97.9\%) (Table 1). Comparing the HA gene of the 5 examined strains with the HA gene of some vaccinal strains that commonly used in Egypt (A/duck/Potsdam/1402/86, $\mathrm{A} /$ chicken/Mexico/232/94 and A/Duck/Anhui/1/06); the results revealed that the lowest homology percentages were mentioned with A/chicken/Mexico/232/94 and ranged from 76 to $79.3 \%, 90.8$ to $82.6 \%$ were noticed with A/ duck/Potsdam/1402/86 strainand from 94.2 to $91.8 \%$ were seen with $\mathrm{A} /$ Duck/Anhui/1/06 strain as shown in (table 1).

Table 1. Nucleotide similarity (\%) of HA gene of the isolated strains with Vaccinal strains.

\begin{tabular}{|c|c|c|c|c|c|c|c|c|c|c|c|}
\hline \multirow{11}{*}{ 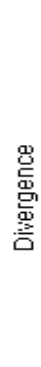 } & \multicolumn{10}{|c|}{ Percent Identity } & \\
\hline & & 1 & 2 & 3 & 4 & 5 & 6 & 7 & 8 & & \multirow{10}{*}{$\begin{array}{l}\text { A-Duck-Egypt-Asy1-2015-ORF } \\
\text { A-Duck-Egypt-Asy2-2015-ORF } \\
\text { A-Duck-Egypt-Asy3-2015-ORF } \\
\text { A-Duck-Egypt-Asy4-2015-ORF } \\
\text { A-Duck-Egypt-Asy5-2015-ORF } \\
\text { HM172115A-duck-Anhui-1-06-H5N1 } \\
\text { AY497096-A-chicken-Mexico-232-94-H5N2 } \\
\text { CY014642-A-duck-Potsdam-1402-6-1986- } 55 N_{7}\end{array}$} \\
\hline & 1 & & 99.2 & 98.0 & 98.0 & 98.1 & 93.7 & 78.0 & 88.1 & 1 & \\
\hline & 2 & 0.7 & & 98.3 & 98.2 & 97.9 & 92.5 & 78.9 & 86.8 & 2 & \\
\hline & 3 & 1.7 & 1.8 & & 98.0 & 98.3 & 94.0 & 78.2 & 87.8 & 3 & \\
\hline & 4 & 1.9 & 1.9 & 1.7 & & 99.6 & 93.8 & 78.8 & 87.7 & 4 & \\
\hline & 5 & 1.9 & 2.1 & 1.6 & 0.4 & & 94.2 & 78.5 & 88.6 & 5 & \\
\hline & 6 & 6.6 & 8.0 & 6.1 & 6.4 & 6.1 & & 79.3 & 90.8 & 6 & \\
\hline & 7 & 26.9 & 25.8 & 26.7 & 25.8 & 26.2 & 25.1 & & 82.6 & 7 & \\
\hline & 8 & 13.3 & 15.0 & 13.5 & 13.7 & 12.7 & 10.0 & 20.4 & & 8 & \\
\hline & & 1 & 2 & 3 & 4 & 5 & 6 & 7 & 8 & & \\
\hline
\end{tabular}

Phylogenetic tree construction revealed the clustering of 5 examined strains into 3 sublineages within clade 2.2.1 HPAI viruses that had been isolated from a chicken and ducks. Also, the examined strains were phylogenetic distant from Egyptian strains isolated in 2006, 2007, 2009, and 2010 (Figure 5). 


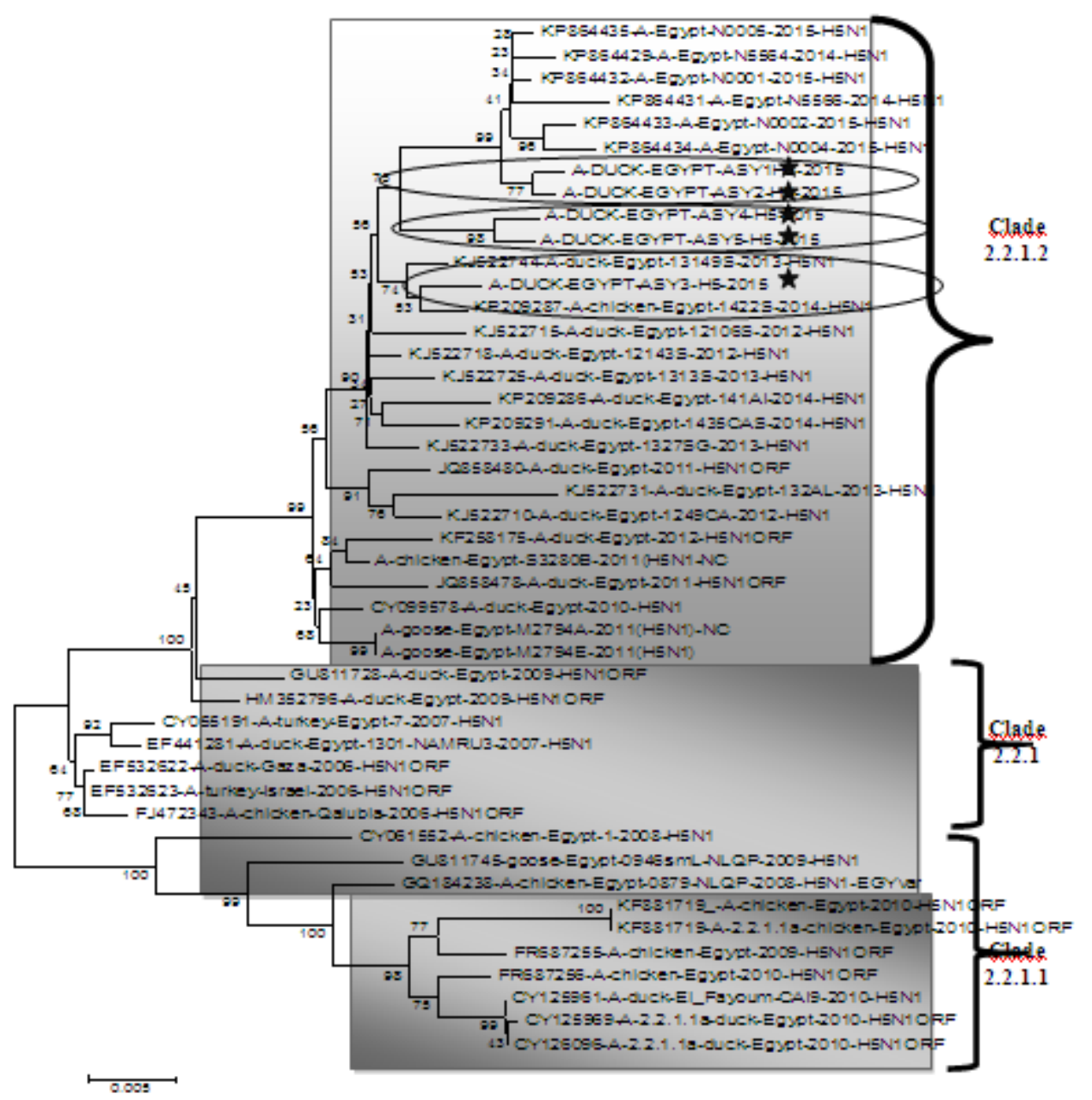

Fig 5. Phylogenetic tree based on the sequence analysis of the entire segment encoding for the HA gene for viruses detected in this study as indicated with black stars using MegAlign (DNASTAR Lasergene 8).

\section{DisCuSSION}

Numerous studies have shown that domestic ducks have played a significant role in the ecology of AIV $(26,27,28)$. However, its role in spreading of AIV is unclear in the Upper Egypt especially Asyut province. In this study, we carried out a trial to identify and characterize the avian influenza that spreads in backyard ducks.

During the collection of samples, the most consistent finding from examining ducks was neurologic clinical signs which may prove its highly pathogenic nature. Neurotropism has been reported as the key finding in many wild Anseriformes experimentally and naturally infected with HPAI-H5N1 viruses[29,30,31]. Bröjer et al. [32] traced these neurologic signs due to meningoencephalomyelitis with the abundant virus in the brain and spinal cord.

Hemagglutinin (HA) is the chief antigen present on the viral surface. It is responsible for viral binding to host receptors, enabling entry into the host cell through endocytosis and consequent membrane fusion. The HA of influenza A virus is highly susceptible to mutations and hence it has a significant role in its pathogenic nature[33].

The Egyptian H5 isolates were classified as clade 2.2.1, which were additionally subdivided into two main groups; group A (classic subclade 2.2.1/C) and group B (variant subclade 2.2.1.1) [34,35,36].

In the present study haemagglutinin (HA) gene sequencing was conducted for five H5 isolates. Based on the existing OIE definition, the molecular mark at the HA cleavage site“ ${ }^{324}{ }^{2}$ KRRRKKR/GLF ${ }^{333}$, when showed in the H5N1 isolated strains, defines these viruses as HPAIH5N1 viruses of clade 2.2.1[37, 38,39] and was found in most Egyptian strains[40]. The deduced amino acids of the 5 examined strains revealed the presence of ${ }^{324}$ EKRRKKR/GLF ${ }^{333}$ motif which became leading from2013 and replaced the previous pattern which disappeared after 2012[24]. 
The Spread and Sequence Exploration of the isolated Avian Influenza viruses H5N1from backyard ducks in Asyut-Egypt

Our findings saw the loss of PGS at 154 (fig. 4) in the examined strains that contributed to increased attraction to human type receptors[41,42].

The H5N1 viruses that isolated from Egypt from 2012 to 2014exhibited four characteristic mutations (D43N, S120(D,N), (S,L)129A, and I151T). Our results displayed that $100 \%$ of the HA sequenced genes had a triple mutation $(129 \Delta, \mathrm{S} 120 \mathrm{D}$, and I151T. These triple mutations are characteristic in 2.2.1.2 clusters that isolated from diverse bird species such as chicken, duck, turkey, geese, ostrich, and quails[43]. In accordance with our results, the 2.2.1.2 viruses were detected previously in Fayoum (37 strains) and Giza (24strains) in Upper Egypt, and 32 strains in Menofia in Lower Egypt[24].

Two mutations of those $(129 \Delta$, I151T) had increased attachment and infectivity to the human lower respiratory tract [44]; that leads an increasing opportunity of human infections.

Despite the applied vaccination programs, the current protocols have limitations and have unsuccessful in providing the expected level of guard against the circulating H5N1viruses belonged to clade 2.2.1 [45,46]. In comparison the sequence of the HA gene of the examined isolates with the sequences ofsome the vaccinal strains were commonly used in Egypt (A/duck/Potsdam/1402/86,A/chicken/Mexico/232/94 and A/Duck/Anhui/1/06); the results (table 1) revealed that the homology percentages were low which ranged from 76 to $79.3 \%$ with $\mathrm{A} /$ chicken/Mexico/232/94 strain, from 90.8 to $82.6 \%$ with A/duck/Potsdam/1402/86 strain and from 94.2 to 91.8 with A/Duck/Anhui/1/06strain.

Veits et al.,[47],de Vries et al.,[48] and Tian et al.,[49]established that the antigenic match between the used vaccines and the current field viruses is one of the most crucial factors in determining the H5 vaccine efficacy to prevent multiplication and spreading of $\mathrm{H} 5 \mathrm{~N} 1$ virus. Kim et al.,[50]stated the malfunction of the vaccine having A/chicken/Mexico/232/94(H5N2)strain to give full protection, was due to antigenic farness of this strain to the HPAI H5N1clades.However, Swayne etal.[51] confirmed that similarity between $\mathrm{H} 5$ vaccine strains and confront viruses did not affect on the virus excretion and defense. Therefore, a yearly assessment of the vaccine efficiency in the face of antigenic change due to the immune stress result from vaccination has been recommended $[52,53,54]$.

\section{Conclusions}

To our awareness, this study affirmed the potential role of backyard ducks as a reservoir for AI/H5N1 clade 2.2.1.2 in Asyut-Egypt which may help in continuation and adaptation of AI/H5N1 virus in the target area and represent a potential danger to both poultry and humans. So, a regular survey to illuminate the spread of HPAIV H5N1 among commercial poultry and household birds should be applied.

\section{Competing interests}

The authors declare that they have no competing interests.

\section{List of abbreviations}

Avian influenza (AI)

hemagglutinin (HA)

highly pathogenic (HPAI)

neuraminidase (NA) gene

phosphate-buffered saline (PBS),

\section{Authors' contributions}

All of the authors contributed to the whole study. Moemen A. Mohamed designed the study, processed and analyzed samples and interpret data, and drafted the manuscript. Mohamed Gamal conducted the fields ampling. All authors reviewed and approved the final manuscript.

\section{Ethics approval}

My manuscript has not studies involving human participants, human data or human tissue so the section of Ethics approval and consent to participate is not applicable in my study 


\section{Consent of publication}

Also to the consent of publication has not any any individual person's data in any form so it is not applicable in my study

\section{Availability of data and materials}

I donot want the data to be available to other due to it my work tha I tired in obtaining it so consider special for me

\section{Funding:}

Poultry Diseases Dept., col vet Med., assiut University, Assiut Egypt

\section{Acknowledgments}

This project was funded by Poultry Diseases Dept., Col Vet Med., Assiut University, Assiut The authors are thankful tothe Dr. Ragab S. Ibrahim and Mostafa E. Saif Eldeen for their help during sampling.

\section{REFERENCES}

[1] David E.S., David L.S. and Leslie D.S., Influenza. In: David E. Swayne, editor. Diseases of poultry. Ames, IO: University Press, 181-218 (2013)

[2] Tong S., Li. Y., Rivailler P., Conrardy C., Castillo D.A., Chen L.M. and et al., A distinct lineage of influenza A virus from bats, Proc Natl Acad Sci USA, 109, 4269-4274 (2012)

[3] Kapczynski D.R., Pantin-Jackwood M., Guzman S.G., Ricardez Y., Spackman E., Bertran K. and et al., Characterization of the 2012 highly pathogenic avian influenzaH7N3 virus isolated from poultry in an outbreak in Mexico: pathobiology andvaccine protection, $J$ Virol., 87(16):9086-96 (2013)

[4] FAO., Approaches to controlling, preventing and eliminating H5N1 Highly pathogenic avian influenza in endemic countries, Rome, (2011)

[5] Webster R.G., Bean W.J., Gorman O.T., Chambers T.M. and Kawaoka Y., Evolution and ecology of influenza A viruses, Microbiol Rev, 56,152-179, (1992)

[6] Songserm T., Jamon R., Sae-Heng N., Meemak N., Hulse-Post D.J., Sturm-Ramirez K.M. and et al., Domestic ducks and H5N1 influenza epidemic, Thailand, Emerg Infect Dis, 12, 575581(2006)

[7] Gilbert M., Chaitaweesub P., Parakarnawongsa T., Premashthira S., Tiensin T., Kalpravidh W. and et al., Free-grazing ducks and highly pathogenic avian influenza, Thailand, Emerg Infect Dis, 12, 227-234 (2006)

[8] Gilbert M., Xiao X., Pfeiffer D., Epprecht M., Boles S., Czarnecki C. and et al., Mapping H5N1 highly pathogenic avian influenza risk in Southeast Asia, Proceedings of the National Academy of Sciences of the United States of America, 105,4769-4774 ( 2008)

[9] Hassan M.K., Jobre Y., Arafa A., Abdelwhab E.M., Kilany W.H., Khoulosy S.G. and et. al., Detection of $\mathrm{A} / \mathrm{H} 5 \mathrm{~N} 1$ virus from asymptomatic native ducks in mid-summer in Egypt, Archives of virology, 158(6), 1361-1365 (2013)

[10] Abdelwhab E. and Hafez H., An overview of the epidemic of highly pathogenic H5N1 avian influenza virus in Egypt: epidemiology and control challenges, Epidemiology and infection, 139(05), 647-57 (2011)

[11] Abdelwhab E.M., Grund C., Aly M.M., Beer M., Harde T.C. and Hafez H.M., Multiple dose vaccination with heterologous $\mathrm{H} 5 \mathrm{~N} 2$ vaccine: Immune response and protection against variant clade 2.2.1 highly pathogenic avian influenza H5N1 in broiler breeder chickens, Vaccine, 29(37), 6219-6225 (2011)

[12] Swayne D.E., The role of vaccines and vaccination in high pathogenicityavian influenza control and eradication, Expert Rev Vaccines, 11(8), 877-80 (2012)

[13] Abdelwhab E.M., Selim A., Arafa A., Galal S., Kilany W., Hassan, M. and et al., Circulation of avian influenza H5N1 in live bird markets in Egypt. Avian diseases, 54(2),911-914 (2010) 
The Spread and Sequence Exploration of the isolated Avian Influenza viruses H5N1from backyard ducks in Asyut-Egypt

[14] Aly M., Arafa A. and Hassan M., Epidemiological findings of outbreaks of diseasecaused by highly pathogenic H5N1 avian influenza virus in poultry in Egypt during 2006, Avian diseases, 52(2), 269-77 (2008)

[15] Hagag I.T., Mansour S.M., Zhang Z. and Ali A.A., Ismaiel EB,Salama AA, et al. Pathogenicity of Highly Pathogenic Avian Influenza Virus H5N1 in Naturally Infected Poultry in Egypt, PLoS ONE, 10(5), e0120061 (2015)

[16] OIE., Manual of diagnostics and vaccines OIE. Manual of diagnostics and vaccines, Chapter 2.03.04 (2014)

[17] Slomka M.J., Pavlidis T., Banks J., Shell W., Mcnally A., Essen S. and et al., Validated H5 Eurasian real-time reverse transcriptase-polymerase chain reaction and its application in H5N1 outbreaks in 2005-2006, Avian diseases, 51, 373-377 (2007)

[18] Tsukamoto K., Ashizawa T., Nakanishi K., Kaji N., Suzuki K., Shishido M. and et al., Use of reverse transcriptase PCR to subtype N1 to N9 neuraminidase genes of avian influenza viruses, J Clin Microbiol., 47(7),2301-3 (2009)

[19] Höper D., Hoffmann B. and Beer M., Simple, sensitive, and swift sequencing of complete H5N1 avian influenza virus genomes, Journal of clinical microbiology, 47(3), 674-679 (2009)

[20] Haghighi H.R., Read L.R., Haeryfar S.M., Behboudi S. and Sharif, S., Identification of a dualspecific T cell epitope of the hemagglutinin antigen of an h5 avian influenza virus in chickens, PLOS ONE, 4(11), e 7772 (2009)

[21] HallT.A., BioEdit: a user-friendly biological sequence alignment editor and analysis for Windows 95/98/NT, Nucleic Acids Symp Ser, 41, 95-98 (1999)

[22] Shih A.C., Hsiao T.C., Ho M.S. and Li, W.H., Simultaneous amino acid substitutions at antigenic sites drive influenza A hemagglutinin evolution, Proc Natl Acad Sci USA, 104, 62836288 (2007)

[23] Cai Z., Ducatez M.F., Yang J., Zhang T., Long L.P., Boon A.C. and et al., Identifying antigenicity-associated sites in highly pathogenic H5N1 influenza virus hemagglutinin by using sparse learning., J Mol Biol., 422,145-155 ( 2012)

[24] Arafa A.S., El-Masry I., Kholosy S., Hassan M.K., Dauphin G., Lubroth J., and Makonnen Y.J., Phylodynamics of avian influenza clade 2.2. 1 H5N1 viruses in Egypt, Virology Journal, 13(1), 1-7 (2016)

[25] El-Shesheny R., Kandeil A., Bagato O., Maatouq A.M., Moatasim Y., Rubrum A. and et al., Molecular characterization of avian influenza H5N1 virus in Egypt and the emergence of a novel endemic subclade, J Gen Virol., 95(7), 1444-1463 (2014)

[26] Huang K., Bahl J., Fan X.H., Vijaykrishna D., Cheung C.L., Webby R.J. and et al., Establishment of an H6N2 influenza virus lineage in domestic ducks in southern China, $J$ Virol., 84, 6978-6986 (2010)

[27] Huang K., Zhu H., Fan X., Wang J., Cheung C.L., Duan L. and et al., Establishment and lineage replacement of H6 influenza viruses indomestic ducks in southern China, J Virol., 86, 6075$6083(2012)$

[28] Deng G., Tan D., Shi J., Cui P., Jiang, Y., Liu L. and et al., Complex reassortment of multiple subtypes of avian influenza viruses in domestic ducks at the Dongting Lake region of China, Journal of virology, 87(17), 9452-9462. (2013)

[29] Keawcharoen J., Van Riel D., Van Amerongen G., Bestebroer, T., Beyer W.E., van Lavieren R. and et al., Wild ducks as long distance vectors of highly pathogenic avian influenza virus (H5N1), Emerg Infect Dis., 14, 600-607 (2008)

[30] Bröjer C., Agren E.O., Uhlhorn H., Bernodt K., Morner T., Jansson D.S. and et al., Pathology of natural highly pathogenic avian influenza $\mathrm{H} 5 \mathrm{~N} 1$ infection in wild tufted ducks (Aythya fuligula), J Vet Diagn Invest., 21, 579-587 (2009)

[31] Nemeth N.M., Brown J.D., Stallknecht D.E., Howerth E.W., Newman S.H., Swayne D.E., Experimental Infection of Bar-Headed Geese (Anser indicus) and Ruddy Shelducks (Tadorna ferruginea) With a Clade 2.3.2 H5N1 Highly Pathogenic Avian Influenza Virus. Veterinary Pathology, 50(6), 961-70 (2013) 
[32] Bröjer C., van Amerongen G., van de Bildt M., van Run P., Osterhaus A., Gavier-Widén D. and et al., Pathogenicity and tissue tropism of currently circulating highly pathogenic avian influenza A virus (H5N1; clade 2.3.2) in tufted ducks (Aythya fuligula), Veterinary microbiology, 180(3), 273-280 (2015)

[33] Anwar T., Lal Sunil K. and Khan U., In silico analysis of genes Nucleoprotein, Neuramidase and Hemagugglutinin: A comparative study on different strains of influeza A (Bird Flu) virus Subtype H5N1, J Silico Biol., 6, 161-168 (2006)

[34] Arafa A.S., Suarez D.L., Hassan M.K. and Aly M.M., Phylogenetic analysis of hemagglutinin and neuraminidase genes of highly pathogenic avian influenza H5N1 Egyptian strains isolated from 2006 to 2008 indicates heterogeneity with multiple distinct sublineages, Avian Dis., 54, 345-349 (2010)

[35] Abdel-Moneim A.S., Shehab G.M. and Abu-Elsaad A.A., Molecular evolution of the six internal genes of H5N1 equine influenza A virus, Arch Virol., 156, 1257-1262 (2011)

[36] Arafa A.S., Hagag N., Erfan A., Mady W., El-Husseiny M., Adel A. and et al., Complete genome characterization of avian influenza virus subtype H9N2 from a commercial quail flock in Egypt, Virus genes, 45(2), 283-294 (2012)

[37] Ducatez M., Olinger C., Owoade A., De Landtsheer S., Ammerlaan W., Niesters H. and et al., Avian flu: multiple introductions of H5N1 in Nigeria, Nature, 442, 37 (2006)

[38] Garten W. and Klenk H.D., Cleavage activation of the influenza virus hemagglutinin and its role in pathogenesis, 156-167. (2008)

[39] Gohrbandt S., Veits J., Hundt J., Bogs J., Breithaupt A., Teifke J.P. and et al., Amino acids adjacent to the haemagglutinin cleavage site are relevant for virulence of avian influenza viruses of subtype H5, Journal of General Virology, 92(1), 51-59 (2011)

[40] Kayali G., Webby R.J., Ducatez M.F., El Shesheny R.A., Kandeil A.M., Govorkova E.A. and et al., The epidemiological and molecular aspects of influenza H5N1 viruses at the human-animal interface in Egypt, PLoS ONE, 6 e17730 (2011)

[41] Gao Y., Zhang Y., Shinya K., Deng G., Jiang Y., Li Z. and et al., Identification of amino acids in $\mathrm{HA}$ and PB2 critical for the transmission of H5N1 avian influenza viruses in a mammalian host, PLoS Pathog, 5(12), e1000709. (2009)

[42] Chen L.M., Blixt O.,Stevens J., Lipatov A.S.,Davis C.T.,Collins B.E. and et al., In vitro evolution of H5N1 avian influenza virus toward human-type receptor specificity, Virology, 422(1),105-113 (2012)

[43] Ibrahim M., Eladl A.F., Sultan H.A., Arafa A.S., Razik A.G., El Rahman S.A., ... and Lee, C.W., Antigenic analysis of $\mathrm{H} 5 \mathrm{~N} 1$ highly pathogenic avian influenza viruses circulating in Egypt (2006-2012), Veterinary microbiology, 167(3), 651-661 (2013)

[44] Watanabe Y., Ibrahim M.S., Ellakany H.F., Kawashita N., Mizuike R., Hiramatsu H. and et al., Acquisition of Human-Type Receptor Binding Specificity by New H5N1 Influenza Virus Sublineages during Their Emergence in Birds in Egypt, PLoS Pathog., 7:19 (2011)

[45] Bahgat M.M., Kutkat M.A., Nasraa M.H., Mostafa A., Webby R., Bahgat I.M. and et al., Characterization of an avian influenza virus H5N1 Egyptian isolate, J Virol Methods, 159(2), 244-250 (2009)

[46] Peyre M., Samaha H., Makonnen, Y.J., Saad A., Abd-Elnabi A., Galal S. and et al., Avian influenza vaccination in Egypt: limitations of the current strategy, J Mol Genet Med., 3(2),198204 (2009)

[47] Veits J., Römer-Oberdörfer A., Helferich D., Durban M., Suezer Y., Sutter, G. and et al., Protective efficacy of several vaccines against highly pathogenic H5N1 avian influenza virus under experimental conditions, Vaccine, 26(13), 1688-1696 (2008)

[48] de Vries R.P., de Vries E., Bosch B.J., de Groot R.J., Rottier P.J. and de Haan C.A., The influenza A virus hemagglutinin glycosylation state affects receptor-binding specificity, Virology, 403(1), 17-25 (2010)

[49] Tian G., Zeng X., Li Y., Shi J. and Chen H., Protective Efficacy of the H5 Inactivated Vaccine Against Different Highly Pathogenic H5N1 Avian Influenza Viruses Isolated in China and Vietnam, Avian Dis., 54, 287-289 (2010) 
The Spread and Sequence Exploration of the isolated Avian Influenza viruses H5N1from backyard ducks in Asyut-Egypt

[50] Kim H.R., Park C.K., Lee Y.J., Woo G.H., Lee K.K., Oem J.K. and et al., An outbreak of highly pathogenic H5N1 avian influenza in Korea, 2008, Vet Microbiol., 141, 362-6 (2010)

[51] Swayne D.E., Brown C., and Bolin C., Understanding the ecology and epidemiology of avian influenza viruses: implications for zoonotic potential, "Emerging diseases of animals, 101-130 (2000)

[52] Spackman E., Swayne D.E., Pantin-Jackwood M.J., Wan X.F., Torchetti M.K., Hassan M. and et al., Variation in protection of four divergent avian influenza virus vaccine seed strains against eight clade 2.2.1 and 2.2.1.1. Egyptian H5N1 high pathogenicity variants in poultry, Influenza and other respiratory viruses, 8(6), 654-662. (2014)

[53] van den Berg T., Lambrecht B., Marche S., Steensels M., Van Borm S. and Bublot M., Influenza vaccines and vaccination strategies in birds. Comp Immunol Microbiol Infect Dis., 31, 121-165 (2008)

[54] Swayne D.E., Pavade G., Hamilton K., Vallat B. and Miyagishima K., Assessment of national strategies for control of high-pathogenicity avian influenza and low-pathogenicity notifiable avian influenza in poultry, with emphasis on vaccines and vaccination, Rev Sci Tech. ,30,839$870,(2011)$ 